\title{
The current role of imaging in the prenatal diagnosis of fetal achondroplasia: medical management and dental implications
}

\author{
George Ion $^{1}$, Cristina-Crenguta Albu ${ }^{2}$, Dinu-Florin Albu ${ }^{3}$ \\ ${ }^{1}$ Dr. George Ion, DMD, PhD Student in Dental Medicine, Assist. Professor of Prosthetic Dentistry, ${ }^{2}$ Dr. Cristina- \\ Crenguta Albu, MD, PhD, Ass. Professor, Ophthalmology and Medical Genetics, ${ }^{3}$ Dr. Dinu-Florin Albu, MD, Ph.D, Ass. \\ Professor, Obstetrics \& Gynecology and Medical Genetics, Expert in Maternal-Fetal Ultrasound and Maternal-Fetal \\ Medicine; all are affiliated with University of Medicine and Pharmacy "Carol Davila", Bucharest, Romania.
}

Address for Correspondence: Dr. Cristina-Crenguta Albu, 27A, Catedrei Street, 1st District, Bucharest, Romania. Email: stevealbu@yahoo.com

\begin{abstract}
We present the case of a patient with the following diagnosis: 29 weeks pregnancy in evolution, fetal achondroplasia with orofacial manifestations: macrocephaly, domed forehead, depressed nasal bridge, maxillary hypoplasia and general manifestations: short fingers, swelling of the back of the hand, increased angle between the femoral head and the femoral shaft, dorsal swelling of the foot, micromelia. The diagnosis was established prenatally after an ultrasound complex investigation and confirmed postnatally. We emphasize the increasingly important current role of the prenatal ultrasound investigation in early diagnosis of congenital anomalies like fetal achondroplasia and in the correct multidisciplinary management of cases.
\end{abstract}

Key words: Fetal achondroplasia, ultrasound investigation, prenatal diagnosis, craniofacial features, dentistry

\section{Introduction}

Skeletal dysplasias are disorders characterized by abnormal growth and remodeling of cartilage and bone. Achondroplasia is considered as a form of skeletal dysplasia dwarfism that manifests with stunted stature and disproportionate limb shortening [1].

Achondroplasia is one of the oldest known birth defects. The average frequency of achondroplasia worldwide is about one case per 25,000 births [2]. It is an inherited disease that causes most types of dwarfism. In about $75 \%$ of cases, the disease has a genetic determinism [3]. Achondroplasia is transmitted as an autosomal dominant trait with complete penetrance [4,5] and approximately $80 \%$ of cases are due to de novo dominant mutations. Achondroplasia is characterized by abnormal growth of bones, the affected patients having short stature, short disproportionate arms and legs. Achondroplasia is of dental interest because of its characteristic craniofacial features which include

Manuscript received: $7^{\text {th }}$ March 2017

Reviewed: $16^{\text {th }}$ March 2017

Author Corrected: $24^{\text {th }}$ March 2017

Accepted for Publication: $31^{\text {st }}$ March 2017 relative macrocephaly, depressed nasal bridge and maxillary hypoplasia $[1,6,7]$. These characteristics may lead to number of complications including hydrocephalus, apnea, upper-airway obstruction, otitis media, sinusitis and dental malocclusion [8,9]. Other associated comorbidities include clubbed feet and adenotonsillar hypertrophy [10]. Hydrocephalus is concerning due to the chronological changes in the eruption of teeth, changes in occlusion, greater accumulation of plaque, and a higher caries prevalence [11]. Regular dental visits are needed to control caries as well as to educate the caregivers regarding oral hygiene needs for children with hydrocephalus. In addition, the dental practitioner needs to be aware of the danger of placing pressure on the ventricular-peritoneal drainage tube during dental treatment. [11,12]. The mortality rate is high for all ages. Children under 4 years can die of skull base compression, patients between 5 and 24 years old can encounter respiratory and central nervous system conditions, and cardiovascular problems may occur to people over 25 years old [12]. 


\section{Case Report}

The purpose of this case report is to present the current role of imaging in the prenatal ultrasound diagnosis of a fetus with systemic achondroplasia and discuss special consideration that should be taken in the case of dental management of this condition. The pregnant woman, aged 33 years with ongoing pregnancy (29 weeks) comes to the hospital for a specialized ultrasound exam. It is the first pregnancy of a Caucasian non-consanguineous couple with a normal general health.

\section{Methods}

A Voluson E8 ultrasound, mode 3D/4D life, was used for investigation. The ultrasound investigation revealed the following results:

Skull with biparietal head diameter: $85.8 \mathrm{~mm}$ (corresponding to 34 weeks), occipitofrontal head diameter: $101.7 \mathrm{~mm}$ (corresponding to 34 weeks), head circumference: $293 \mathrm{~mm}$. Macrocephaly, (Figure 1), Domed forehead, (Figure 2), Depressed nasal bridge and Maxillary hypoplasia.

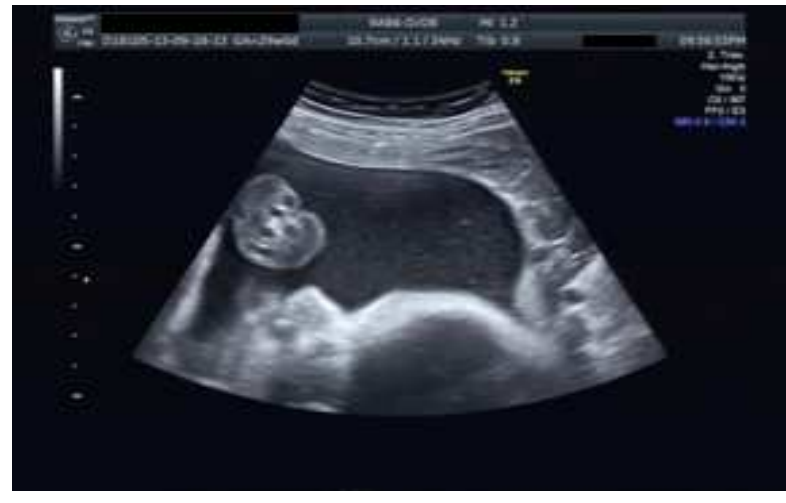

Figure-1: Macrocephaly

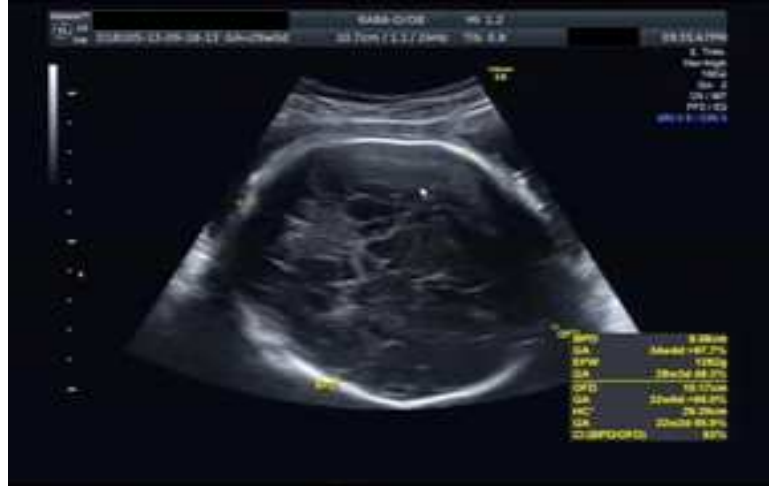

Figure-2: Domed forehead

The thorax showed apparently normal shape and structure (corresponding to 30 weeks), anterior-posterior diameter: 72.2 $\mathrm{mm}$ and transverse diameter: $76.4 \mathrm{~mm}$. The abdomen showed an apparently normal conformation (corresponding to 30 weeks), anterior-posterior diameter: $72.7 \mathrm{~mm}$; transverse diameter: $91.6 \mathrm{~mm}$; Abdominal circumference: $259.2 \mathrm{~mm}$. Upper limbs: Humerus: $40.9 \mathrm{~mm}$ (corresponding to 24.6 weeks). Ulna: $41 \mathrm{~mm}$ (corresponding to 26.5 weeks). Radius: $37.5 \mathrm{~mm}$ (corresponding to 26.2 weeks). Short fingers. Swelling of the back of the hand (Figure 3). Legs: Femur: 43.7 $\mathrm{mm}$ (corresponding to 24.2 weeks). Tibia: $39.3 \mathrm{~mm}$ (slightly curved) (corresponding to 25 weeks). Fibula: $37.7 \mathrm{~mm}$ (corresponding to 24.2 weeks). Increased angle between the femoral head and the femoral shaft $\left(130^{\circ}\right)$ (Figure 4). Dorsal swelling of the foot (Figure 5). Micromelia.

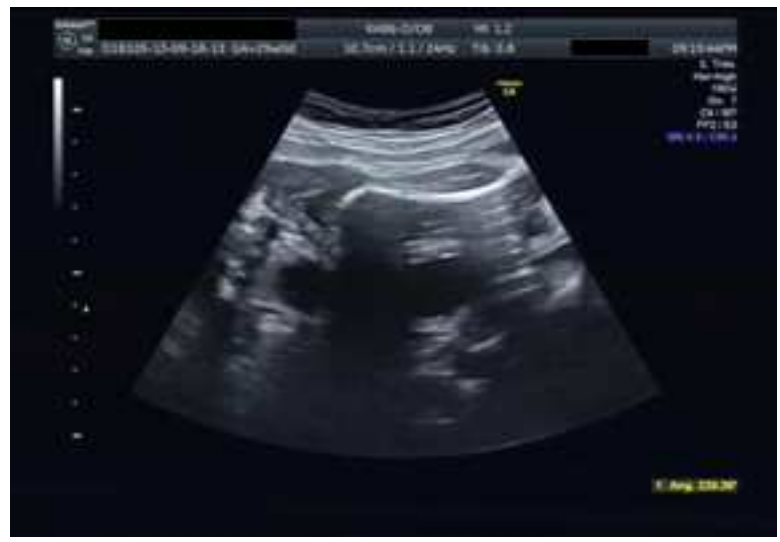

Figure-3: Swelling of the back of the hand

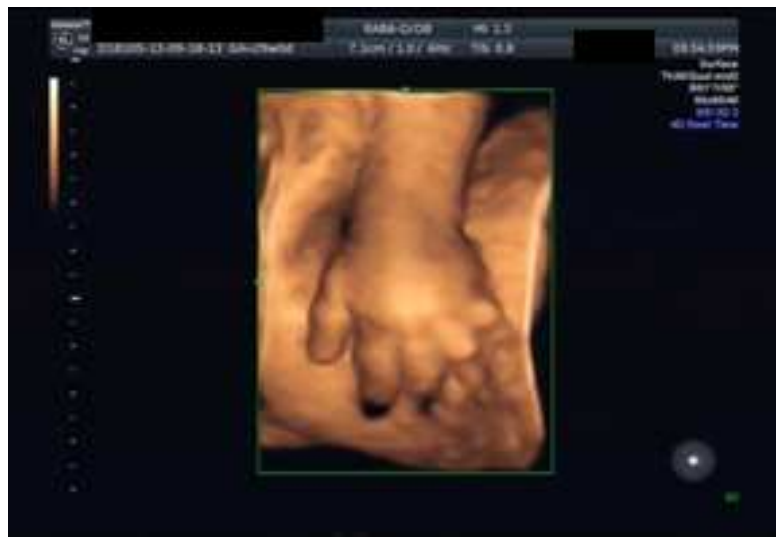

Figure-4: Increased angle between the femoral head and the femoral shaft 


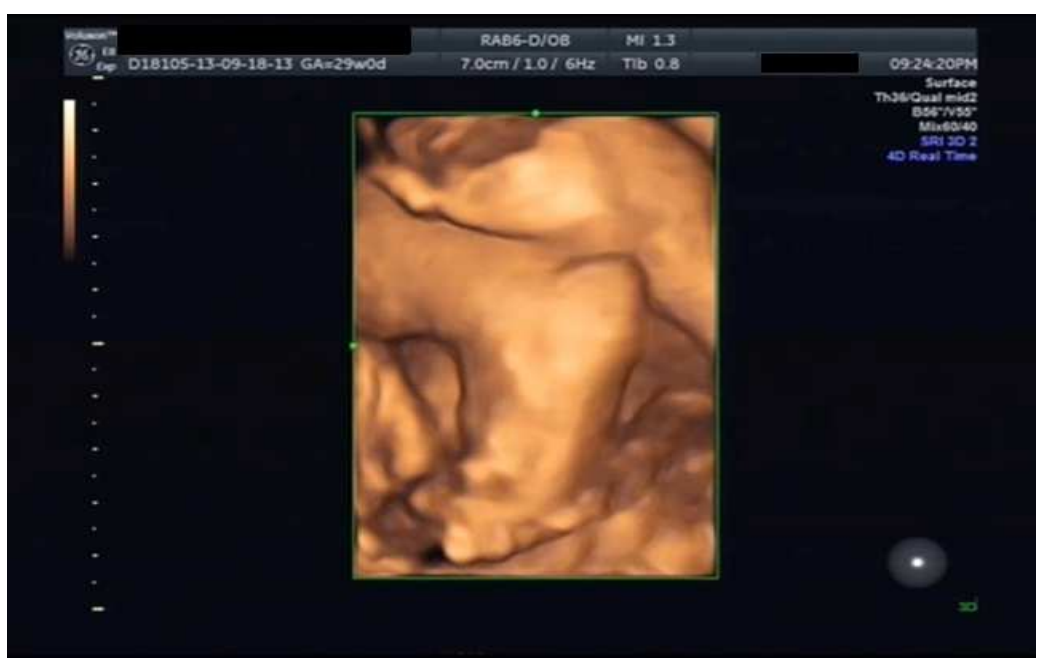

Figure-5: Dorsal swelling of the foot

After the ultrasound investigation the following diagnosis was established: Pregnancy 29 weeks in evolution. Fetal achondroplasia with Macrocephaly, Domed forehead, Depressed nasal bridge, Maxillary hypoplasia, Short fingers, Swelling of the back of the hand, Increased angle between the femoral head and the femoral shaft, Dorsal swelling of the foot, Micromelia, Estimated weight: $1270 \mathrm{~g}$.

The detected prenatal diagnosis was confirmed postpartum. Because of early complications, severe respiratory insufficiency, the baby was died 6 days after birth.

\section{Discussion}

Achondroplasia also known as Chondrodystrophia fetalis is a non-lethal form of chondrodysplasia, with general physical features and craniofacial features. $[1,13]$.

Achondroplasia is of special interest in the field of dentistry because of its characteristic craniofacial features which include relative macrocephaly with hydrocephaly, depressed nasal bridge and maxillary hypoplasia.

Hydrocephaly, is characterized by accumulation of cerebrospinal fluid in the lateral ventricles of the brain causing progressive ventricular dilatation. It has been reported that patients with achondroplasia and hydrocephaly can present chronological changes in the eruption of their teeth, changes in the occlusion, greater accumulation of plaque, and have a higher caries prevalence.

Typically, there is no delay in the eruption sequence of primary or permanent teeth. [14,15].

However, due to the jaw structure and small stature, teeth are sometimes larger than the jaw can support.
Patients with achondroplasia are somewhat prone to gingivitis [16] and periodontal disease [17]. If children require general anesthesia for dental work, there may be concern with enlarged adenoids or small nasal pharynxes and larynxes causing difficulty for the anesthesia to be successful [18].

Moreover, there are situations of malocclusion due to crowding, and children with achondroplasia need to be monitored by an orthodontist to assist with spacing, occlusal interferences, and difficulty with speech. American Academy of Pediatrics recommends review of orthodontic problems in achondroplasia after 5 years of age [19].

Dealing with achondroplastic children needs special psychological management during dental treatment, as the presence of disproportionate short stature can cause a number of psychosocial and social problems [7, 19].

It is imperative to consider the accommodations needed for dental patients with achondroplasia. The office should evaluate the height of the front desk, office area, and restroom facilities, as well as the operatory accessibility [20]. 


\section{Conclusions}

The importance of ultrasound imaging investigation for the accurate prenatal diagnosis of congenital anomalies and correct management of the case is to be noted $[21,22]$.

This case study report provides important information about the conditions of achondroplasia and perspective o people with achondroplasia. Dentists should be aware of the clinical features of achondroplasia and the complications of this genetic disorder [23].

A patient with achondroplasia requires specific multidisciplinary management, psychological social and familly support to help him lead a normal life.

\section{Funding: Nil, Conflict of interest: None Permission of IRB: Yes}

\section{References}

1. Rohilla S, Kaushik A, Vinod VC, Tanwar R, Kumar M. Orofacial manifestations of achondroplasia. EXCLI J. 2012 Aug 27;11:538-42. eCollection 2012.

2. Orioli IM, Castilla EE, Barbosa-Neto JG. The birth prevalence rates for the skeletal dysplasias. J Med Genet. 1986 Aug;23(4):328-32.

3. Rousseau F, Bonaventure J, Legeai-Mallet L, Pelet A, Rozet JM, Maroteaux P, Le Merrer M, Munnich A. Mutations in the gene encoding fibroblast growth factor receptor-3 in achondroplasia. Nature. 1994 Sep 15;371 (6494):252-4

4. Jones KL. Achondroplasia Smith's recognizable patterns of human malformation. 4th. Philadelphia, PA: WB Saunders; 1988.

5. Gorlin RJ, Cohen MM, Levin LS. Syndromes of the head and neck. 3rd. New York: Oxford University Press; 1990.

6. Shirley ED, Ain MC. Achondroplasia: manifestations and treatment. J Am Acad Orthop Surg. 2009 Apr; 17 (4):231-41.

7. Al-Saleem A, Al-Jobair A. Achondroplasia: Craniofacial manifestations and considerations in dental management. The Saudi Dental Journal. 2010; 22, 195-199.
8. Steinbok P, Hall J, Flodmark O. Hydrocephalus in achondroplasia: the possible role of intracranial venous hypertension. J Neurosurg. 1989 Jul;71(1):42-8.

9. Hunter AG, Bankier A, Rogers JG, Sillence D, Scott CI Jr. Medical complications of achondroplasia: a multicentre patient review. J Med Genet. 1998 Sep;35 (9): 705-12.

10. Richardson N. Achondroplasia. Physiopedia. 1-8. Available at: www. physio-pedia.com/Achondroplasia. Accessed April 30, 2014.

11. de Morais Gallarreta FW, Bernardotti FP, de Freitas AC, de Queiroz AM, Faria G. Characteristics of individuals with hydrocephalus and their dental care needs. Spec Care Dentist. 2010 Mar-Apr;30(2):72-6. doi: 10.1111/j.1754-4505.2009.00122.x.

12. Jennifer S. Sherry, Sophia Aponte. Oral health concerns associated with genetic disorder commonly referred to as dwarfism. RDH, Volume 35, Issue 8, August 26, 2015.

13. Langer LO Jr, Baumann PA, Gorlin RJ. Achondroplasia. Am J Roentgenol Radium Ther Nucl Med. 1967 May; 100(1):12-26.

14. Vaccaro A.R.,Albert T.J. Thieme Medical Publication; New York: 2001. Master Cases: Spine Surgery. p. 481.

15. Onodera K., Sakata H., Niikuni N., Nonaka T., Kobyashi K., Nakazima I. Survey of the present status of sleep-disordered breathing in children with achondroplasia, Part I. A questionnaire survey. IJPORL. 2005;69:457-461.

16. Wagaiyu EG, Ashley FP. Mouthbreathing, lip seal and upper lip coverage and their relationship with gingival inflammation in 11-14 year-old schoolchildren. J Clin Periodontol. 1991 Oct;18(9):698-702.

17. Stephen L, Holmes H, Roberts T, Fieggen K, Beighton P. Orthodontic management of achondroplasia in South Africa. S Afr Med J. 2005 Aug;95(8):588-9.

18. Aldegheri R, Dall'Oca C. Limb lengthening in short stature patients. J Pediatr Orthop B. 2001 Jul;10(3): 238-47. 
19. Trotter TL, Hall JG; American Academy of Pediatrics Committee on Genetics. Health supervision for children with achondroplasia. Pediatrics. 2005 Sep; 116(3):771-83.

20. Aldegheri R, Dall'Oca C. Limb lengthening in short stature patients. J Pediatr Orthop B. 2001 Jul; 10 (3): 238-47.

21. Oncescu, A., Albu, D. and Albu, C. The utility of the echographic exam in detection of cromosomal abnormalities and other plurimarformative syndromes associated with Dandy Walker syndrome: review of 15 cases in 2012. Ultrasound Obstet Gynecol, 2013; 42: 149. doi:10.1002/uog.13039

22. Albu, C., Albu, D. and Oncescu, A. Prenatal ultrasound diagnosis and follow up treatment of a giant lateral abdominal wall hemangioma. Ultrasound Obstet Gynecol, 2013; 42: 139. doi:10.1002/uog.13006.

23. Baujat G, Legeai-Mallet L, Finidori G, CormierDaire V, Le Merrer M. Achondroplasia. Best Pract Res Clin Rheumatol. 2008 Mar; 22(1):3-18. doi: 10.1016/j. berh. 2007.12.008.

\section{How to cite this article?}

George Ion, Cristina-Crenguta Albu, Dinu-Florin Albu. The current role of imaging in the prenatal diagnosis of fetal achondroplasia:medical management and dental implications. Int J Med Res Rev 2017;5(03):363-367 doi:10.17511/ijmrr. 2017.i03.24. 